\begin{tabular}{|c|c|c|c|c|c|c|}
\hline \multirow{4}{*}{ Impact Factor: } & ISRA (India) & 3.117 & SIS (USA) & $=0.912$ & ICV (Poland) & $=6.630$ \\
\hline & ISI (Dubai, UAE & $=0.829$ & РИНЦ (Russia & $=0.156$ & PIF (India) & $=1.940$ \\
\hline & GIF (Australia) & $=0.564$ & ESJI (KZ) & $=5.015$ & IBI (India) & $=4.260$ \\
\hline & JIF & $=1.500$ & SJIF (Morocco & $=5.667$ & & \\
\hline
\end{tabular}

\begin{tabular}{|c|c|}
\hline $\begin{array}{l}\text { SOI: } 1.1 / 7 \\
\text { International S } \\
\text { Theoretical } \mathbb{\&}\end{array}$ & $\begin{array}{l}\frac{\mathrm{AS}}{\mathrm{DO}} \mathrm{D}: \underline{10.15863 / \mathrm{TAS}} \\
\text { ientific Journal } \\
\text { pplied Science }\end{array}$ \\
\hline p-ISSN: 2308-4944 (print) & e-ISSN: 2409-0085 (online) \\
\hline Year: 2018 & Volume: 68 \\
\hline Published: 26.12 .2018 & ttp://T-Science.org \\
\hline
\end{tabular}

SECTION 11. Biology. Ecology. Veterinary. UDC: 611.318:611.018.7:616.311.2
QR - Issue

QR - Article

\author{
UDC: 611.318:611.018.7:616.311.2
}
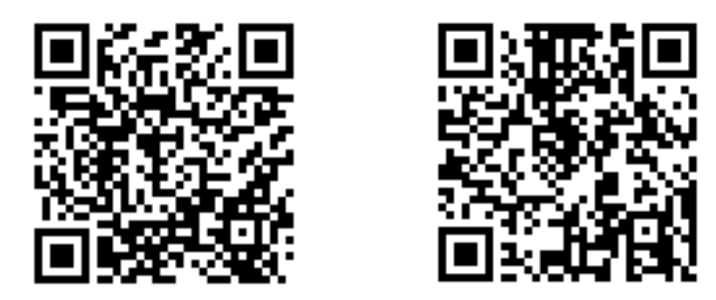

Denis Nikolaevich Drozdov

Ph.D. in Biological Sciences, Associate Professor Gomel State University named Skaryna

\author{
Alla Vasil'evna Reutskaya \\ chemistry teacher \\ Public education institution \\ "Secondary school №15 of Gomel"
}

\title{
CYTOMORPHOMETRY OF BUCCAL EPITHELIUM FOR SMOKING YOUNG PEOPLE BY THE METHOD OF ASSESSING NUCLEAR CYTOPLASMATIC RELATIONS
}

\begin{abstract}
The paper presents the results of a cytomorphological analysis of the cells of the buccal epithelium of smoking and non-smoking young people, which made it possible to evaluate the reliability of the influence of the smoking factor on the morphometric characteristics of oral mucosa cells. As a result of the analysis, a significant difference was found between the average values of the nuclear-cytoplasmic ratio in the cells of smoking and nonsmoking students. The smoking factor has a significant effect on the structural cellular morphogenesis, which is aimed at reducing the area of the cytoplasm and increasing the area of the cell nucleus, the influence of the factor is estimated at $90 \%$. Such dynamics of nuclear cells may indicate an increase in cell proliferative activity, which occurs against the background of a chronic load from the components of tobacco smoke.

Key words: buccal epithelium, nuclear-cytoplasmic ratio.

Language: Russian

Citation: Drozdov, D. N., \& Reutskaya, A. V. (2018). Cytomorphometry of buccal epithelium for smoking young people by the method of assessing nuclear cytoplasmatic relations. ISJ Theoretical \& Applied Science, 12 (68), 242-247.

Soi: http://s-o-i.org/1.1/TAS-12-68-35 Doi: crossef https://dx.doi.org/10.15863/TAS.2018.12.68.35

\section{ЦИТОМОРФОМЕТРИЯ БУККАЛЬНОГО ЭПИТЕЛИЯ КУРЯЩИХ МОЛОДЫХ ЛЮДЕЙ МЕТОДОМ ОЦЕНКИ ЯДЕРНО-ЦИТОПЛАЗМАТИЧЕСКОГО ОТНОШЕНИЯ}

Аннотация: В статье представлены результаты циитоморфологического анализа клеток буккального эпителия курящих и некурящих молодых людей, который позволил оценить достоверность влияния фактора курения на морфометрические характеристики клеток слизистой оболочки полости рта. В результате анализа было обнаружено достоверное различие между средними значениями ядерноцүитоплазматического отношения в клетках курящих и некурящих студентов. Фактор курения оказывает значимое влияние на структурный клеточный морфогенез, который направлен на уменьшение площади цитоплазмы и увеличение площчади клеточного ядра, влияние фактора оченивается в 90 \%. Такая динамика клеточных структур слизистой оболочки щеки указывает на увеличение пролиферативной активности, возникающей на фоне хронической нагрузки от компонентов табачного дыма.

Ключевые слова: буккальный эпителий, ядерно-цчитоплазматическое отношение.
\end{abstract}

Введение.

Одной из актуальных проблем, которая вызывает научно-практический интерес, является негативное влияние курения и те многочисленные негативные последствия, которые формируются в молодом организме. Фактор курения молодых людей определяет не только медицинскую, но и социальную значимостью этой проблемы, что подтверждают многочисленные исследования, научные проекты, национальные и международные программы [1]. 


\begin{tabular}{|c|c|c|c|c|c|c|}
\hline \multirow{4}{*}{ Impact Factor: } & ISRA (India) & $=3.117$ & SIS (USA) & $=0.912$ & ICV (Poland) & $=6.630$ \\
\hline & ISI (Dubai, UAE & $=0.829$ & РИНЦ (Russia) & $=0.156$ & PIF (India) & $=1.940$ \\
\hline & GIF (Australia) & $=0.564$ & ESJI (KZ) & $=\mathbf{5 . 0 1 5}$ & IBI (India) & $=4.260$ \\
\hline & JIF & $=1.500$ & SJIF (Morocco) & $=5.667$ & & \\
\hline
\end{tabular}

Мониторинг молодежной среды в возрасте 15 - 19 лет показывает, что число курящих достигает $40-45 \%$

(Постоялко Л. А., 2005, Александров А. А., 2009). Фактор курения является массовой социальной и психоэмоциональной проблемой. Особая актуальность изучения негативного влияния курения рассматривается относительно состояния слизистой оболочки ротовой полости и явления клеточного перестройки буккального (щечного) эпителия, которое развивается в условиях действия экзогенных факторов табачного дыма. Направленность исследований на буккальный эпителий связана с тем, что именно слизистая оболочка ротовой полости и верхних дыхательных путей служат первым барьером, которые внешнему подвергается воздействию.

Многочисленные современные исследования [2-8], дают возможность выделить буккальный эпителий, как уникальный объект изучения, позволяющий дать оценку состоянию не только ротовой полости, но и целым системам в организме человека. В этой связи особый интерес вызывают работы [9], которые изучают механизмы малигнизации (трансформации) эпителиальных клеток. Трансформационные перестройки клеточной структуры приводят к еще мало изученным функциональным изменениям и влекут за собой возможные формы клеточных патологий. В научной литературе подробно описаны изменения, происходящие в слизистой ротовой полости курящих людей (Ахаладзе $\mathrm{H}$. Г.,1999, Быков В. Л., 1997, Латышева С. В., 2003). Отдельного внимания заслуживают данные о том, что фактор табачного дыма может являться причиной предракового состояния слизистой оболочки рта (Гасюк Н. В., 2014, Bagan J. V., 2003, Bornstein M. M., 2004).

В силу своих анатомических и гистологических особенностей слизистая оболочка полости рта, как и верхние дыхательные пути, являются первым барьером на пути воздействия химических компонентов табачного дыма и соединений никотина. В перечень химических компонентов табачного дыма входят более чем 4000 веществ, среди которых канцерогены (бензол, формальцегид, бензопирен) и токсичные вещества (мышьяк, кадмий, полоний210, цианистый водород и др.). Многослойный плоский неороговевающий эпителий щеки регулярно обновляется за счет клеток базального слоя. По мере своего роста базальные эпителиоциты постепенно поднимаются в поверхностный слой и проходят шесть стадий клеточной дифференцировки (Юй, 2006). Вступая во взаимодействие с компонентами табачного дыма, в условиях продолжающейся дифференцировки клетки претерпевают морфологические нарушения, одним из которых является изменение размера ядра и соотношения ядра и цитоплазмы (ЯЦО). Появление измененных клеток в буккальном эпителии может свидетельствовать о наличие воспалительный процесс или формировании злокачественного новообразования.

Согласно материалу [8] клетки буккального эпителий содержат около $5 \%$ гликогена, имеют вид тонких пластинок и полигональную либо овальную форму. Размеры клеток 48 - 142 мкм, в среднем около 89 мкм, площадь клеток 2000 -

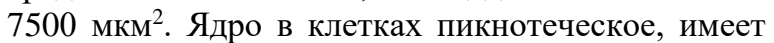
круглую либо овоидную форму располагается, как правило, эксцентрично поверхностного слоя, его размеры составляют 8-15 мкм, площадь $28-90$ мкм $^{2}$. Цитоплазма клеток равномерно прокрашивается, начиная с увеличения х400, видно, что она имеет мелкую исчерченность. Согласно публикации [10] оптимальное ЯЦО для одноядерной соматической клетки эпителия составляет $1: 50, \quad 1: 60, \quad 1: 80$. Используя представленные меры количественных оценок для клеток можно провести сравнительную оценку цитоморфологического состояния эпителия курящих и некурящих молодых людей.

Цель работы: провести сравнительный анализ и оценить цитоморфологическое состояние буккального эпителия курящих и некурящих молодых людей с помощью ядерноцитоплазматического соотношения.

\section{Материалы и методы исследования}

Цитологическое исследование буккального эпителия проведено в период 2017 - 2018 гг. в группе из 24 учащихся старших классов (средний возраст 16 лет, юноши) средней общеобразовательной школы. Среди молодых людей было проведено анонимное анкетирование, позволившее определить отношение к курению и стаж курения. Выборочная группа была разделена на три категории: некурящие (негативное отношение к курению), курящие (стаж курения 1 2 лет), курящие и использующие иные препараты, травмирующие слизистую ротовой полости (каждая группа составляла 6 человек). Для сокращения были введены условные обозначение категорий обследованных нами лиц: первая категория - без стажа курения (БСК), вторая низкий стаж курения (НСК), третья - высокий стаж курения (ВСК). При проведении обследования отдельное внимание было уделено гигиеническому состоянию слизистой ротовой полости. Для этой цели производился визуальный осмотр состояния десен и слизистой оболочки щек, а также верхней и нижней губы. При осмотре фиксировали наличие повреждений, язв, наличие кистообразных пузырьков.

Перед забором биологического материала, производили предварительный осмотр и 


\begin{tabular}{|c|c|c|c|c|c|c|}
\hline \multirow{4}{*}{ Impact Factor: } & ISRA (India) & $=3.117$ & SIS (USA) & $=0.912$ & ICV (Poland) & $=6.630$ \\
\hline & ISI (Dubai, UAE & $=0.829$ & РИНЦ (Russia) & $=0.156$ & PIF (India) & $=1.940$ \\
\hline & GIF (Australia) & $=0.564$ & ESJI (KZ) & $=\mathbf{5 . 0 1 5}$ & IBI (India) & $=4.260$ \\
\hline & JIF & $=1.500$ & SJIF (Morocco) & $=5.667$ & & \\
\hline
\end{tabular}

заполнение протокола обследования гигиенического состояния ротовой полости. Материалом для исследования служили мазки буккального эпителия, который собирали несколько раз металлическим шпателем с внутренней стороны щеки и переносили на предметное стекло, после чего высушивали на открытом воздухе с фиксацией в этаноле 15 минут. После чего мазки окрашивали гематоксилин-эозином [11] и определяли морфометрические показателей клеток буккального эпителия методом световой микроскопии на микроскопе NiconECLIPSE 80i при увеличении х400. С помощью программы ScopePhoto получил фотографии окрашенных препаратов от каждого обследованного. Цитоморфометрию ядра и цитоплазмы проводили c помощью программы «PhotoM», которая позволила определить продольные и поперечные размеры клеток при заданном разрешении. Произведения продольных и поперечных размеров ядра и цитоплазма использовали вместо площади этих структур, для последующего расчета ЯЦО по формуле (1):

$$
\text { ЯЦО = Ая / Sц }
$$

где Sя - площадь ядра клетки, мкм; Sц площадь цитоплазмы, мкм.

Для статистической обработки полученных данных использовали проверку нормальности распределения, путем оценки отношения коэффициентов асимметрии и эксцесс к их стандартным ошибкам. Достоверность различий вариационных рядов определяли исходя из нормальности распределения с помощью tкритерия Стьюдента. Достоверность различия оценивали для уровня значимость 0,05 .

\section{Результаты и их обсуждение.}

Данные морфометрии буккальных клеток, которые мы получили в каждой группе, позволили оценить статистические характеристики и нормальность распределения площади цитоплазма, ядра и ядерно-цитоплазматического индекса. Для оценки характера распределения значений использовали тест КолмогороваСмирнова с поправкой Лиллиефорса для уровня значимости 0,05. Результаты теста показали достоверное соответствие выборочных значений в каждой группе нормальному распределению, как для показателей площади цитоплазмы, так и для площади ядра $(p>0,20)$. Дополнительной проверкой служили показатели асимметрии и эксцесс и отношения к стандартным ошибкам, значение которых не превышали табличных значений для требуемого уровня значимости. В таблице 1 представлены основные характеристики распределений площади цитоплазмы эпителия у учащихся разных групп.

Таблица 1. Морфометрия цитоплазмы клеток буккального эпителия.

\begin{tabular}{|l|c|c|c|}
\hline Группа & S, мкм & Асимметрия & Эксцесс \\
\hline БСК & $\begin{array}{c}3114,70 \\
\pm 7,72 \\
(21,56)\end{array}$ & $\begin{array}{c}0,59 \\
\pm 0,43\end{array}$ & $\begin{array}{c}0,31 \\
\pm 0,36\end{array}$ \\
\hline НСК & $\begin{array}{c}2720,12 \\
\pm 6,15 \\
(17,20)\end{array}$ & $\begin{array}{c} \pm, 33 \\
\pm 0,65\end{array}$ & $\begin{array}{c} \pm 0,43 \\
\pm 0,32\end{array}$ \\
\hline ВСК & $\begin{array}{c}2215,00 \\
\pm 6,41 \\
(17,94)\end{array}$ & $\begin{array}{c}-0,25 \\
\pm 0,91\end{array}$ & $\begin{array}{c}-0,83 \\
\pm 0,57\end{array}$ \\
\hline
\end{tabular}

Из таблицы 1 видно, что площадь цитоплазмы эпителиоцитов некурящих учащихся достоверно больше, чем в группе курящих, по сравнению со второй группой - на $14,5 \%$, с третьей группой - на $40,6 \%$. Наблюдается некоторая общая тенденция снижения вариационного размаха и величины асимметрии. Для группы некурящих учащихся имеет место левосторонняя асимметрия (As >0), для группы курящих - правосторонняя асимметрия (As < 0) площади цитоплазмы. Для распределения площади цитоплазмы клеток у некурящих учащихся характерна высоковершинность (Еs >0), которая указывает на скопление частот в области среднего значения. Для курящих характерна низковершинность распределения (Es $<0$ ), что говорит о бо́льшей степени разброса вариационного ряда, чем в группе некурящих. В 


\begin{tabular}{|c|c|c|c|c|c|c|}
\hline \multirow{4}{*}{ Impact Factor: } & ISRA (India) & $=3.117$ & SIS (USA) & $=0.912$ & ICV (Poland) & $=6.630$ \\
\hline & ISI (Dubai, UAE & $=0.829$ & РИНЦ (Russia) & $=0.156$ & PIF (India) & $=1.940$ \\
\hline & GIF (Australia) & $=0.564$ & ESJI (KZ) & $=\mathbf{5 . 0 1 5}$ & IBI (India) & $=4.260$ \\
\hline & JIF & $=1.500$ & SJIF (Morocco) & $=5.667$ & & \\
\hline
\end{tabular}

таблице 2 представлены результаты оценки эпителия у учащихся разных групп. распределения показателей площади ядро

Таблица 2. Морфометрия ядра клеток буккального эпителия

\begin{tabular}{|c|c|c|c|}
\hline Группа & S, мкм & Асимметрия & Эксцесс \\
\hline \multirow{2}{*}{ БСК } & $\begin{array}{c}51,69 \\
\pm 3,45 \\
(9,66)\end{array}$ & $\begin{array}{c}0,31 \\
\pm 0,43\end{array}$ & $\begin{array}{c}0,21 \\
\pm 0,83\end{array}$ \\
\hline \multirow{2}{*}{ НСК } & $\begin{array}{c} \pm 6,81 \\
(12,70)\end{array}$ & $\begin{array}{c}-0,34 \\
\pm 0,33\end{array}$ & $\begin{array}{c}-0,56 \\
\pm 0,35\end{array}$ \\
\hline \multirow{2}{*}{ ВСК } & $\begin{array}{c} \pm 9,58 \\
\pm 4,43\end{array}$ & $\begin{array}{c}-0,40 \\
\pm 0,56\end{array}$ & $\begin{array}{c}-0,85 \\
\pm 0,27\end{array}$ \\
\hline
\end{tabular}

Из таблицы 2 видна обратная тенденция площадь ядра у курящих учащихся больше, чем у некурящих учащихся. Площадь ядра в группе ВСК на 73,3 \% больше, чем в группе БСК, и на $34,1 \%$ больше чем в группе НСК. Величина вариационного размаха и показатели формы распределения достоверно уменьшается в направление от группы БСК к группе ВСК. Полученные результаты достаточно хорошо согласуются с данными приведенными в работах $[8,11,12]$. Статистический анализ результатов таблицы 1 и 2 позволяет утверждать о том, что у курящих молодых людей наблюдается смещение ядерно-цитоплазматического отношения в сторону ядра. Полученная закономерность свидетельствует о структурных функциональных нарушениях, развивающихся в клетках эпителия слизистой оболочки ротовой полости. В таблице 3 представлены средние значения и показатели вариации ЯЦО клеток эпителия учащихся разных групп.

Таблица 3. Ядерно-цитоплазматические отношения буккального эпителия

\begin{tabular}{|c|c|c|c|}
\hline Индекс & БСК & НСК & ВСК \\
\hline OHI-S [14] & $0-0,6$ & $0,7-1,6$ & $>1,6$ \\
\hline ЯЦО & $\begin{array}{c}0,0166 \pm 0,0011 \\
(0,0031)\end{array}$ & $\begin{array}{c}0,0246 \pm 0,0017 \\
(0,0047)\end{array}$ & $\begin{array}{c}0,0495 \pm 0,0020 \\
(0,0056)\end{array}$ \\
\hline Вариация ЯЦО & $18,6 \%$ & $19,1 \%$ & $11,3 \%$ \\
\hline
\end{tabular}

\begin{abstract}
Данные таблицы 3 подтверждают полученную закономерность, а также свидетельствуют о достоверном различии средних значений ЯЦО клеток эпителия учащихся разных групп. Применение однофакторного
\end{abstract}

дисперсионного анализа (ANOVA) показало, что процент разброса отношения межгрупповой дисперсии к общей для ЯЦО клеток эпителия составил $90 \%$, что говорит о выраженном влиянии фактора табачного дыма на слизистую 


\begin{tabular}{|c|c|c|c|c|c|c|}
\hline \multirow{4}{*}{ Impact Factor: } & ISRA (India) & $=3.117$ & SIS (USA) & $=0.912$ & ICV (Poland) & $=6.630$ \\
\hline & ISI (Dubai, UAE & $=0.829$ & РИНЦ (Russia & $=0.156$ & PIF (India) & $=1.940$ \\
\hline & GIF (Australia) & $=0.564$ & ESJI (KZ) & $=5.015$ & IBI (India) & $=4.260$ \\
\hline & JIF & $=1.500$ & SJIF (Morocco & $=5.667$ & & \\
\hline
\end{tabular}

оболочку ротовой полости курящих молодых людей.

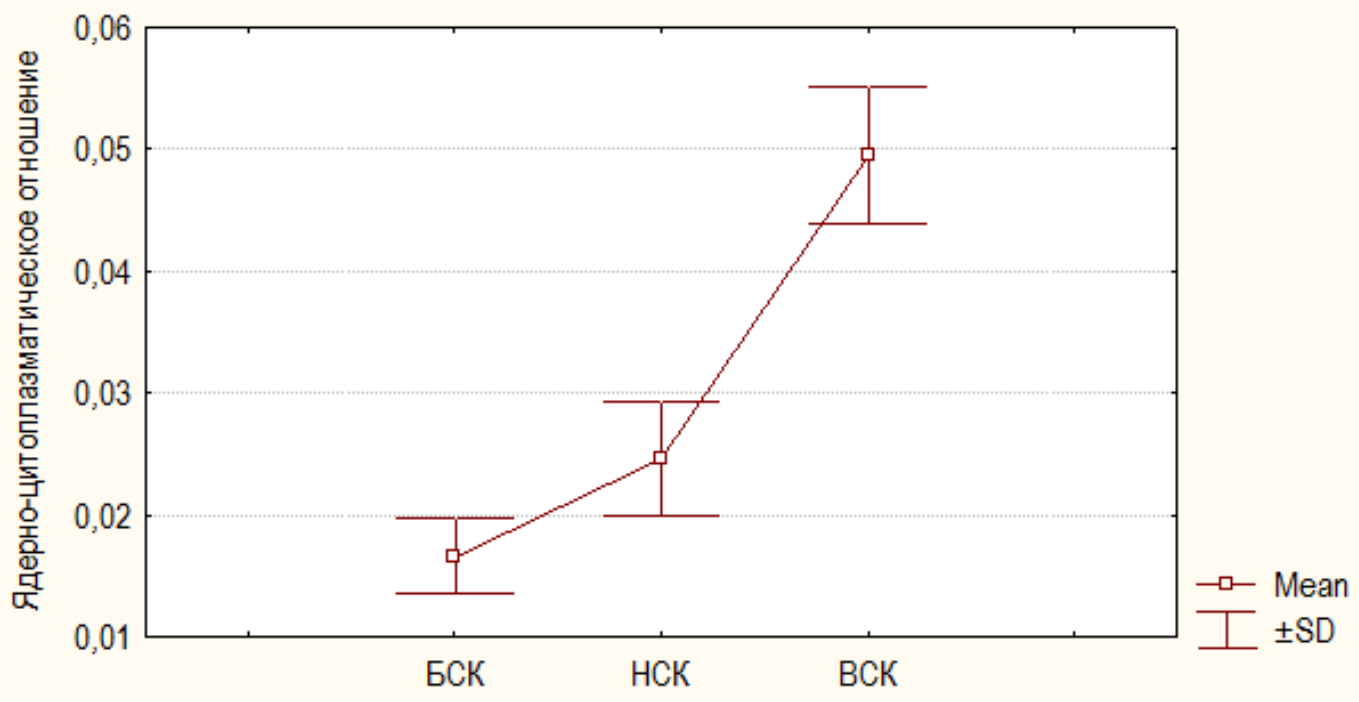

Рисунок 1 - Распределение ЯЦО клеток буккального эпителия

На рисунке 1 представлены распределения ЯЦО буккального эпителия учащихся разных групп. Из рисунка видно четкое отклонение границ распределения ЯЦО учащихся, имеющих высокий стаж курения от границ распределения некурящих учащихся. Значения ЯЦО у курящих в 3 раза больше, чем у некурящих молодых людей. Наблюдается достоверное отклонение данного показателя от верхней границы нормы.

\section{Заключение.}

Цитоморфологической анализ клеток буккального эпителия курящих и некурящих молодых людей позволил оценить достоверность влияние фактора курения на морфометрические характеристики клеток слизистой оболочки ротовой полости. В результате анализа установлено достоверное различие между средними значениями ядерноцитоплазматического отношения в клетках курящих и некурящих учащихся. Фактор курения оказывает достоверное влияние на структурный клеточный морфогенез, который направлен на уменьшение площади цитоплазмы и увеличение площади клеточного ядра, сила влияния фактора оценивается в $90 \%$. Подобная динамика ЯЦО может свидетельствовать о росте пролиферативной активности клеток, которая происходит на фоне хронической нагрузки со стороны компонентов табачного дыма. Кроме того, сдвиг ЯЦО в сторону ядра указывает на наличие компенсаторных реакций и сбой в клеточном метаболизме, способный спровоцировать развитие патологических состояний.

\section{References:}

1. Vartonyan, F. E., \& Shahovskij, K. P. (2003). VOZ i bor'ba s kureniem v mire: strategii i tendencii. Narkologiya, №4, 2-4.

2. Kovalev, V. N., \& Karpova, S. S. (2004). Citogeneticheskij monitoring: metody ocenki zagryazneniya okruzhayushchej sredy $i$ sostoyaniya geneticheskogo apparata organizma. (p.80). Voronezh.
3. Yurchenko, V. V. (2005). Citogeneticheskie narusheniya $\mathrm{v}$ epitelii shcheki cheloveka pri ekspozicii genotoksikantami. Toksikol. vestn., № 6, 14-21.

4. Husainova, I. S., Varulev, I. Y., \& Kozhina, N. A. (1997). Ocenka citologicheskih pokazatelej bukkal'nogo epiteliya dlya diagnostiki funkcional'nogo sostoyaniya 


\begin{tabular}{|c|c|c|c|c|c|c|}
\hline \multirow{4}{*}{ Impact Factor: } & ISRA (India) & $=3.117$ & SIS (USA) & $=0.912$ & ICV (Poland) & $=6.630$ \\
\hline & ISI (Dubai, UAI & $=0.829$ & РИНЦ (Russia) & $=0.156$ & PIF (India) & $=1.940$ \\
\hline & GIF (Australia) & $=0.564$ & ESJI (KZ) & $=5.015$ & IBI (India) & $=4.260$ \\
\hline & JIF & $=1.500$ & SJIF (Morocco) & $=5.667$ & & \\
\hline
\end{tabular}

cheloveka. Klinicheskaya laboratornaya diagnostika, № 3, 10-12.

5. Yuj, R. I. (2006). Citologicheskij analiz slizistoj obolochki polosti rta kak dostovernyj kriterij ocenki ee gistofiziologii, patologii i effektivnosti lecheniya. Vestnik KazNMU, Vyp. 1, 299-314.

6. Abadzhidi, M. A., Mahrova, T. V., Mayanskaya, I. V., Zaslavskaya, M. I., Strogova, Y. Y., \& Mayanskij, A. N. (2003). Bukkal'nye epiteliocity kak instrument klinikolaboratornyh issledovanij. (pp.13-14). Medikum.

7. Gasyuk, N. V. Moshel', T. N., \& Popovich, I. Y. (2016). Osobennosti kachestvennoj i kolichestvennoj perestrojki kletochnogo sostava bukkal'nogo epiteliya $\mathrm{v}$ usloviyah nikotinovoj intoksikacii. Ukrainskij stomatologicheskij al'manah, № 1 (tom 1), 1620.
8. (n.d.). Retrieved Nov. 01, 2018, from http://www.atmpractica.ru/sudebnayameditsina/ issledovanieepitelialnoytkani.html

9. Bykov, V. L. (1997). Funkcional'naya morfologiya epitelial'nogo bar'era slizistoj obolochki polosti rta. Stomatologiya, № 3, 1217.

10. Gill, G. U. (2015). Klinicheskaya citologiya : teoriya i praktika citotekhnologii. per. s angl. In: A. V. Bezrukova, K. T. Kasoyan (Eds.). (p.383). Moskva: Prakticheskaya medicina.

11. Morozova, E. N., Tverskoj, A. V., Asadov, R. I., \& Morozov, V. N. (2018). Morfologicheskie osobennosti bukkal'nogo epiteliya u studentov negroidnoj rasy, imeyushchih razlichnyj uroven' gigieny polosti rta. Vestnik medicinskih tekhnologij, № 4, 18-26.

12. Latysheva, S.V., Zastenchik, N. A., \& Astapenko, Y. P. (1998). Sostoyanie polosti rta u kuryashchih. Zdravoohranenie, № 2, 28-29. 